University of Nebraska - Lincoln

DigitalCommons@University of Nebraska - Lincoln

Publications, Agencies and Staff of the U.S.

Department of Commerce

U.S. Department of Commerce

2011

Effects of vertical wind shear and cloud radiative processes on responses of rainfall to the large-scale forcing during pre-summer heavy rainfall over southern China

\author{
Xinyong Shen \\ Nanjing University of Information Science and Technology \\ Yi Wang \\ Nanjing University of Information Science and Technology \\ Xiaofan Li \\ NOAA/NESDIS/Center for Satellite Applications and Research
}

Follow this and additional works at: https://digitalcommons.unl.edu/usdeptcommercepub

Part of the Environmental Sciences Commons

Shen, Xinyong; Wang, Yi; and Li, Xiaofan, "Effects of vertical wind shear and cloud radiative processes on responses of rainfall to the large-scale forcing during pre-summer heavy rainfall over southern China" (2011). Publications, Agencies and Staff of the U.S. Department of Commerce. 314.

https://digitalcommons.unl.edu/usdeptcommercepub/314

This Article is brought to you for free and open access by the U.S. Department of Commerce at DigitalCommons@University of Nebraska - Lincoln. It has been accepted for inclusion in Publications, Agencies and Staff of the U.S. Department of Commerce by an authorized administrator of DigitalCommons@University of Nebraska - Lincoln. 


\title{
RMetS
}

Royal Meteorological Society

\section{Effects of vertical wind shear and cloud radiative processes on responses of rainfall to the large-scale forcing during pre-summer heavy rainfall over southern China}

\author{
Xinyong Shen, ${ }^{\mathrm{a}, \mathrm{b} *}$ Yi Wang ${ }^{\mathrm{a}}$ and Xiaofan $\mathrm{Li}^{\mathrm{c}}$ \\ ${ }^{\text {a }}$ Key Laboratory of Meteorological Disaster of Ministry of Education, Nanjing University of Information Science and \\ Technology, Nanjing, Jiangsu, China \\ ${ }^{\mathrm{b}}$ Department of Atmospheric and Oceanic Science, University of Maryland, College Park, Maryland, USA \\ ${ }^{\mathrm{c}}$ NOAA/NESDIS/Center for Satellite Applications and Research, Camp Springs, Maryland, USA \\ ${ }^{\star}$ Correspondence to: Xinyong Shen, College of Atmospheric Sciences, Nanjing University of Information Science and \\ Technology, Nanjing, Jiangsu, 210044, China. E-mail: shenxy@nuist.edu.cn
}

The pre-summer heavy rainfall over southern China during 3-8 June 2008 is simulated using a two-dimensional cloud-resolving model. The model is integrated with imposed zonally uniform vertical velocity, zonal wind, horizontal temperature and vapour advection from National Centers for Environmental Prediction (NCEP)/Global Data Assimilation System (GDAS) data. The effects of vertical wind shear and cloud radiative processes on the response of rainfall to largescale forcing are analysed through the comparison of two sensitivity experiments with the control experiment. One sensitivity experiment excludes the large-scale vertical wind shear and the other excludes the cloud radiative effects. During the decay phase of convection, the increase in model domain-mean surface rain-rate resulting from the exclusion of vertical wind shear is associated with the slowdown in the decrease of perturbation kinetic energy due to the exclusion of barotropic conversion from mean kinetic energy to perturbation kinetic energy. The increase in domain-mean rain-rate from the exclusion of cloud radiative effects is related to the enhancement of condensation and associated latent heat as a result of strengthened radiative cooling. The increase in the domain-mean surface rain-rate is mainly associated with the increase of convective rainfall, which is in turn related to the local atmospheric change from moistening to drying. During the onset and mature phases of convection, the domain-mean surface rain-rates are generally insensitive to vertical wind shear and cloud radiative effects whereas convective and stratiform rain-rates are sensitive to vertical wind shear and cloud radiative effects. The decrease in convective rain-rate and the increase in stratiform rain-rate are primarily associated with the enhanced transport of hydrometeor concentration from convective regions to raining stratiform regions. Copyright (C) 2011 Royal Meteorological Society

Key Words: cloud-resolving model simulation; convective and stratiform rain-rates; vertical wind shear; cloud radiative effects; budget analysis

Received 12 November 2009; Revised 16 March 2010; Accepted 2 August 2010; Published online in Wiley Online Library 20 January 2011

Citation: Shen X, Wang Y, Li X. 2011. Effects of vertical wind shear and cloud radiative processes on responses of rainfall to the large-scale forcing during pre-summer heavy rainfall over southern China. Q. J. R. Meteorol. Soc. 137: 236-249. DOI:10.1002/qj.735 


\section{Introduction}

The pre-summer rainy season is the major rainy season over southern China (Ding, 1994a). The rainfall starts in early April and reaches its peak in June. The torrential rainfall can lead to tremendous property damage and fatalities. For example, in 1998 the torrential rainfall resulted in more than \$US 30 billion in damage and over 100 fatalities. Thus, it is important to further understand the southern China presummer heavy rainfall and associated physical processes. The effects of cold surges over the Southern Hemisphere, cross-equatorial flow from the Southern Hemisphere and monsoon and water vapour transport on pre-summer heavy rainfall have been investigated observationally and numerically (e.g. Krishnamurti et al., 1976; Tao and Ding, 1981; Wang and Li, 1982; Ding, 1994b; Simmonds et al. 1999).

Cloud-resolving models include prognostic cloud microphysical parametrization schemes and their simulation data have been analysed for process studies associated with convective development (e.g. Gao and $\mathrm{Li}, 2008 \mathrm{a}$ ) and for the development of cloud parametrization schemes for climate modelling (e.g. Randall et al., 1996). Gao et al. (2005a) combined water vapour and cloud budgets to derive a diagnostic surface rainfall equation for quantitatively identifying surface rainfall processes in a unified framework that links precipitation, clouds and environmental thermodynamic conditions. They found that while the water vapour processes largely account for the variations in surface rain-rate, the cloud processes play significant roles in these variations. The analysis of the surface rainfall budget has been intensively applied to cloud-resolving model simulation data to study the role of surface evaporation in surface rainfall processes (e.g. Cui and Li, 2006), diurnal variations of tropical convective and stratiform rainfall (e.g. Cui, 2008; Cui and Li, 2009; Ping and Luo, 2009), precipitation efficiency (e.g. Sui et al., 2007), and the sensitivity of convective and stratiform rainfall to sea-surface temperature (e.g. Zhou and $\mathrm{Li}$ 2009). Recently, Gao and Li (2008b) examined responses of tropical deep convective precipitation systems and their associated convective and stratiform regions to strong and weak imposed large-scale upward motions by analysing a two-dimensional (2D) cloud-resolving model simulation during Tropical Ocean-Global Atmosphere Programme Coupled Ocean-Atmosphere Response Experiment (TOGA COARE), and found that the convective rainfall is not sensitive to the large-scale forcing whereas stronger upward motions produce stronger stratiform rainfall than weaker upward motions do.

The effects of vertical wind shear on convective development have been examined for decades (e.g. Pastushkov, 1975; Corbosiero and Molinari, 2002; Lang et al., 2007; Ueno, 2007). The delayed initiation of convection is associated with a strong vertical wind shear (e.g. Xu et al., 1992). The vertical wind shear affects convective development by changing vertical transport of horizontal momentum (e.g. Wu and Yanai, 1994). The convection becomes increasingly organized in lines as a result of a strong lower-tropospheric vertical wind shear (e.g. Robe and Emanuel, 2001). The negative vertical wind shear led to wellorganized convection and strong convective precipitation during a landfall of severe tropical storm Bilis (2006) (Wang et al., 2009b).
Cloud radiative processes have important impacts on surface rainfall. The infrared (IR) cooling can increase surface rain-rate by $14 \%$ and $31 \%$ in simulations of squalls over the midlatitudes and Tropics, respectively (Tao et al., 1993). The clear-sky IR cooling increases the surface rainrate by $15 \%$ whereas the reduction in the IR cooling rate by the anvil cirrus decreases the surface rain-rate by $10 \%$ (Fu et al., 1995). The diurnal variation of oceanic precipitation may be insensitive to the cloud-radiation interaction (Xu and Randall, 1995). The IR cooling during night-time reduces saturation specific humidity and can result in the nocturnal rainfall peak (e.g. Sui et al., 1997, 1998). The significant increase of domain-mean surface rainfall is associated with the exclusion of cloud radiative effects (e.g. Gao and Li, 2008a).

In this study, the effects of vertical wind shear and cloud radiative processes on responses of pre-summer heavy rainfall over southern China to the large-scale forcing are examined with $2 \mathrm{D}$ cloud-resolving model simulations. The pre-summer heavy rainfall event over southern China during 3-8 June 2008 is simulated in a control experiment. The two sensitivity experiments with vertical wind shear and cloud radiative effects excluded are conducted and compared with the control experiment. In the next section, model, control and sensitivity experiments, and comparison between the control simulation and observation, are described and discussed. The results are presented in section 3. A summary is given in section 4 .

\section{Model and experiments}

The cloud-resolving model (Soong and Ogura, 1980; Soong and Tao, 1980; Tao and Simpson, 1993) used in this study is the 2D version of the model (Sui et al., 1994, 1998) that was modified by Li et al. (1999). Detailed descriptions of the model can be found in Gao and $\mathrm{Li}$ (2008a). Briefly, the model includes prognostic equations for potential temperature and specific humidity, prognostic equations for mixing ratios of cloud water, raindrops, cloud ice, snow and graupel, and perturbation equations for zonal wind and vertical velocity. The model uses the cloud microphysical parametrization schemes taken from Rutledge and Hobbs (1983, 1984), Lin et al. (1983), Tao et al. (1989) and Krueger et al. (1995). Solar (Chou et al., 1998) and thermal infrared (Chou et al., 1991; Chou and Suarez, 1994) radiation parametrization schemes are performed every minute. The model uses cyclic lateral boundaries, and a horizontal domain of $768 \mathrm{~km}$ with 33 vertical levels, and its horizontal and temporal resolutions are $1.5 \mathrm{~km}$ and $12 \mathrm{~s}$, respectively. The top model level is at $42 \mathrm{hPa}$. The vertical grid resolution ranges from about $40 \mathrm{~m}$ near the surface to about $1 \mathrm{~km}$ near $100 \mathrm{hPa}$. Grabowski et al. (1998) compared sensitivity experiments between $200 \mathrm{~m}$ and $2 \mathrm{~km}$ horizontal resolution and showed similarities in terms of thermodynamic, cloud and rainfall properties. Petch (2006) found that a horizontal grid length of $200 \mathrm{~m}$ or less is needed to capture the most important cloud processes.

The data from the Global Data Assimilation System (GDAS) developed by the National Centers for Environmental Prediction (NCEP), National Oceanic and Atmospheric Administration (NOAA), USA are used to calculate the forcing data for the model over a longitudinally oriented rectangular area of $108-116^{\circ} \mathrm{E}, 21-22^{\circ} \mathrm{N}$ over coastal areas along southern Guangdong and Guangxi provinces and the 

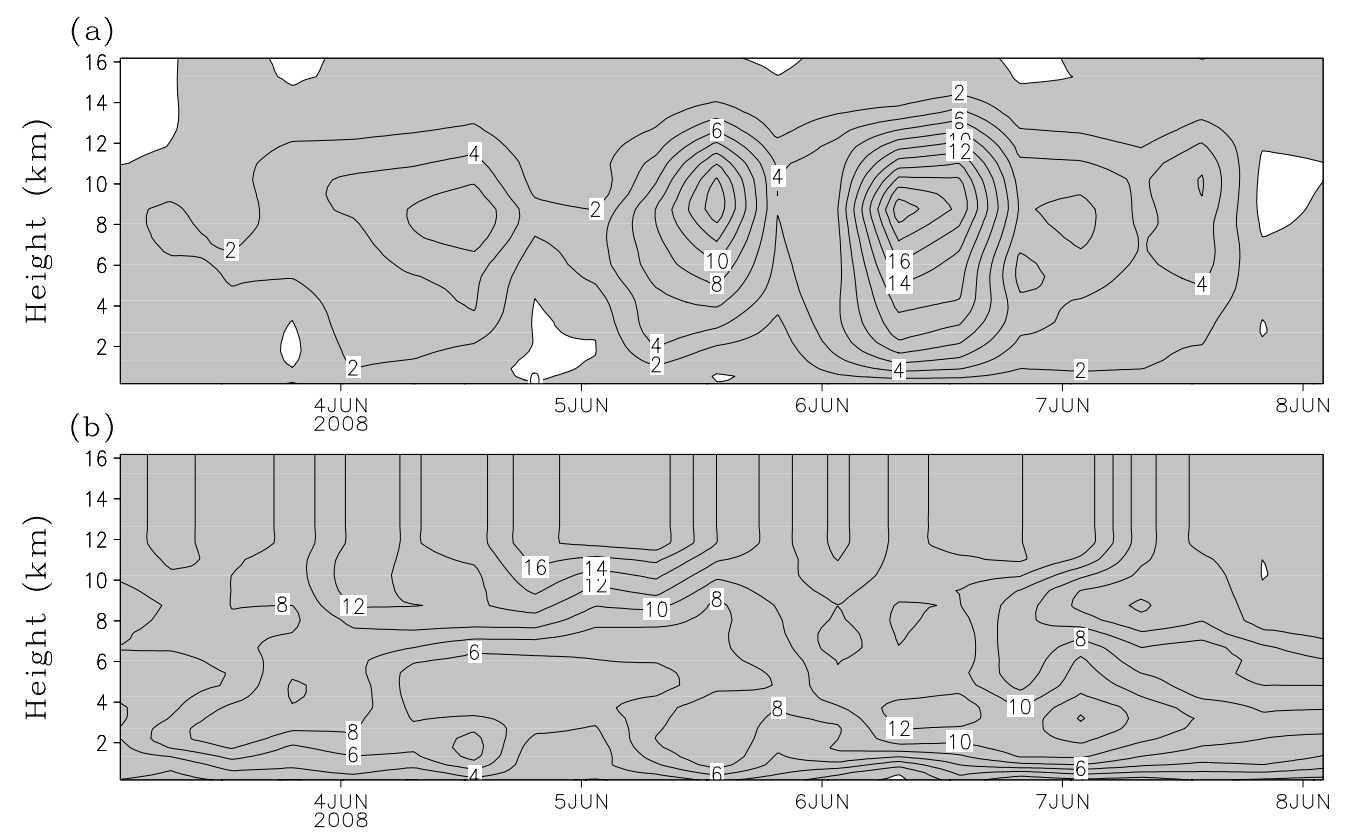

Figure 1. Temporal and vertical distribution of (a) vertical velocity $\left(\mathrm{cm} \mathrm{s}^{-1}\right.$ ) and (b) zonal wind $\left(\mathrm{m} \mathrm{s}^{-1}\right)$ from 0200 LST 3 June to 0200 LST 8 June 2008. The data are averaged in a rectangular box of $108-116^{\circ} \mathrm{E}, 21-22^{\circ} \mathrm{N}$ from NCEP/GDAS data. Ascending motion in (a) and westerly wind in (b) are shaded.

surrounding northern South China Sea. The horizontal and temporal resolutions for NCEP/GDAS products are $1^{\circ} \times 1^{\circ}$ and 6 hourly, respectively. The model is forced by large-scale vertical velocity, zonal wind (Figure 1), and horizontal temperature and water vapour advection (not shown) averaged over $108-116^{\circ} \mathrm{E}, 21-22^{\circ} \mathrm{N}$. The model is integrated from 0200 Local Standard Time (LST: UTC +8 h) 3 June to 0200 LST 8 June 2008 (a total of 5 days) during the pre-summer heavy rainfall. The surface temperature and specific humidity from NCEP/GDAS averaged over the model domain are uniformly imposed on each model grid to calculate surface sensible heat flux and evaporation flux. The 6 hourly zonally uniform large-scale forcing data are linearly interpolated into $12 \mathrm{~s}$ data, which are uniformly imposed zonally over the model domain at each time step. The imposed largescale vertical velocity shows the gradual increase of upward motions from 3 June to 6 June. The maximum upward motion of $18 \mathrm{~cm} \mathrm{~s}^{-1}$ occurred around $9 \mathrm{~km}$ in the late morning of 6 June. The upward motions decreased dramatically on 7 June. The lower-tropospheric westerly winds of 4-12 $\mathrm{m} \mathrm{s}^{-1}$ were maintained during the rainfall event.

In the control experiment $(\mathrm{C})$, the model is integrated with the initial vertical profiles of temperature and specific humidity from NCEP/GDAS at 0200 LST 3 June 2008. It is also integrated with the initial vertical profiles spatially uniformly perturbed by $\pm 0.2^{\circ} \mathrm{C}$ of temperature and $\pm 1 \%$ of specific humidity in four experiments, respectively. The model is integrated with the initial conditions and constant large-scale forcing at 0200 LST 3 June for 6 hours during the model spin-up period and the 6 hour model data are not used for analysis. The five model runs are averaged to form ensemble simulation data for analysis. The simulations in the control experiment $(\mathrm{C})$ are compared with vertical profiles of temperature and specific humidity from NCEP/GDAS (Figure 2) and observed surface rain-rate from rain-gauge stations (Figure 3). The simulated temperatures and specific humidities can be, respectively, $-1^{\circ} \mathrm{C}$ and $-1 \mathrm{~g} \mathrm{~kg}^{-1}$ smaller than those from NCEP/GDAS data, and their root-meansquare (RMS) differences are $0.61^{\circ} \mathrm{C}$ and $0.39 \mathrm{~g} \mathrm{~kg}^{-1}$. The cold and dry biases and RMS differences are significantly smaller than those shown in Li et al. (1999) during TOGA COARE. The comparison in surface rain-rate between the simulation and rain-gauge observations averaged from 17 stations over southern Guangdong and Guangxi reveals a fair agreement with a gradual increase from 3 to 6 June and a rapid decrease from 6 to 7 June (Figure 3). Their RMS difference $\left(0.92 \mathrm{~mm} \mathrm{~h}^{-1}\right)$ is significantly smaller than the standard derivations of simulated $\left(1.28 \mathrm{~mm} \mathrm{~h}^{-1}\right)$ and observed $\left(1.26 \mathrm{~mm} \mathrm{~h}^{-1}\right)$ rain-rates. The linear correlation between the simulated and observed rain-rates is 0.87 , which is statistically significant. The differences in surface rain-rate between the simulation and observation can reach $2 \mathrm{~mm} \mathrm{~h}^{-1}$, as seen in previous studies (e.g. Li et al., 1999; Xu et al., 2007; Wang et al., 2009a). The differences may partially be from the comparison of small hourly local sampling of rain-gauge observations over $35 \%$ of the model domain over land and no rain-gauge observations over $65 \%$ of the model domain over ocean with large model domain averages of model data in the control experiment with imposed 6 hourly large-scale forcing. The convection may be affected by land-ocean contrast and orography; these effects are included in large-scale forcing imposed on the model.

The two sensitivity experiments carried out in this study use a model with the same imposed large-scale forcing. Experiment CNVWS is identical to the control experiment (C) except that vertically varying large-scale zonal winds in $\mathrm{C}$ are replaced with their mass-weighted means in CNVWS. Experiment CNVWS is compared with C to study the effects of vertical wind shear on rainfall responses to the large-scale forcing. Experiment CNCR is identical to C except that the mixing ratios of five cloud species are set to zero in the calculation of radiation. Experiment CNCR is compared with $\mathrm{C}$ to study cloud radiative effects on rainfall responses to the large-scale forcing. Like the control experiment, CNVWS and CNCR are integrated with both unperturbed 


\section{(a)}
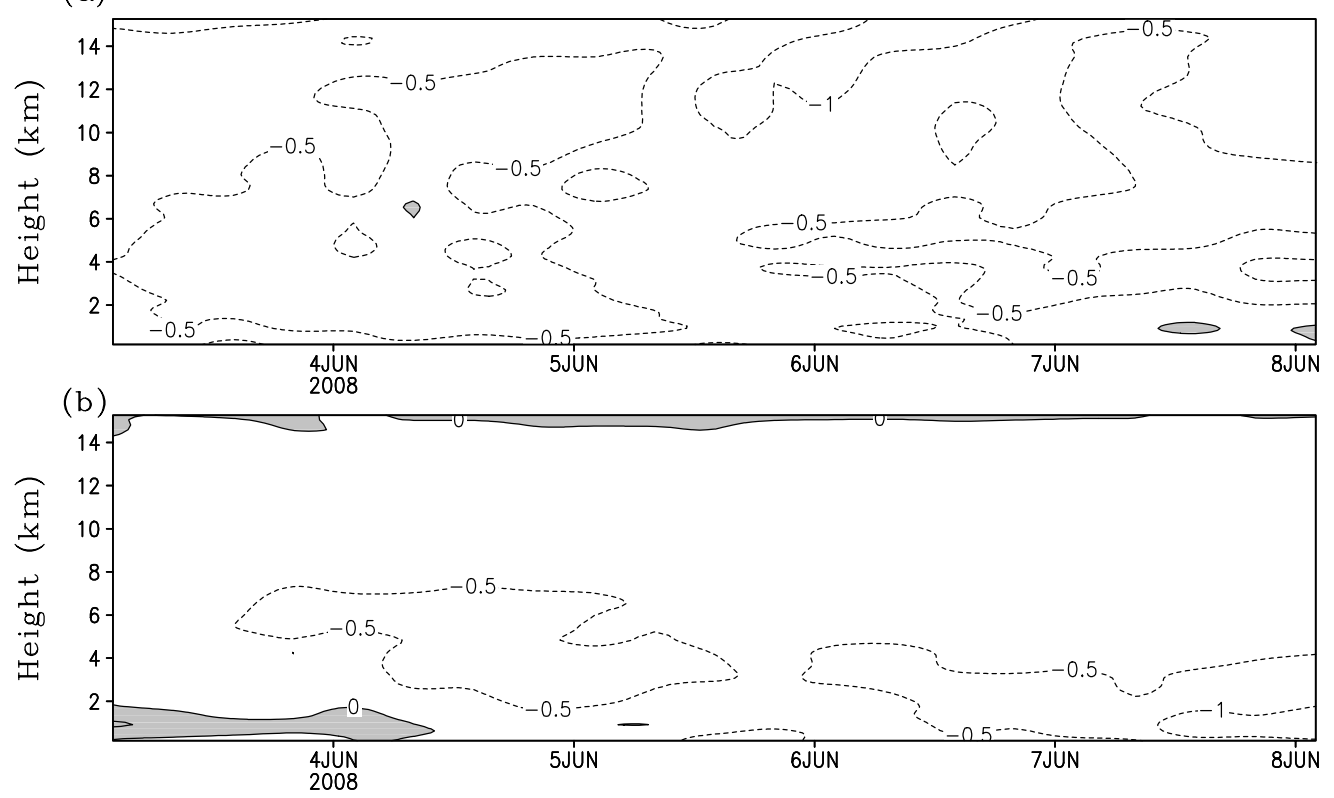

Figure 2. Time-height distributions of (a) temperature difference $\left({ }^{\circ} \mathrm{C}\right)$ and specific humidity difference $\left(\mathrm{g} \mathrm{kg}^{-1}\right)$ between the control experiment and NCEP/GDAS data.

and perturbed initial conditions. The ensemble simulation data are used in the following analysis.

\section{Results}

\subsection{Control experiment}

In the control experiment, the time and model-domain mean surface rain-rate increases from 4 June to 6 June 2008, reaches its maximum on 6 June, and then decreases significantly on 7 June (Figure 3 ). The rainfall processes on 5 June are similar to those on 4 June. Thus, the daily and model-domain mean surface rainfall budgets are calculated on 4, 6 and 7 June (Figure 4). These three days represent the onset, mature and decay phases of presummer heavy rainfall events over southern China. June 4 is characterized by moderate large-scale forcing with domainmean water vapour convergence and heat divergence. June 6 has strong large-scale forcing with domain-mean water vapour convergence and heat divergence while 7 June has weak large-scale forcing with domain-mean water vapour and heat divergence. The surface rainfall equation can be found at (A1) in the appendix. Positive values of $Q_{\text {WVT }}, Q_{W V F}, Q_{W V E}$ and $Q_{\mathrm{CM}}$ denote local atmospheric drying, water vapour convergence, surface evaporation, and decrease in local hydrometeor concentration/hydrometeor convergence, respectively. Note that taking the model domain mean on $Q_{\mathrm{CM}}$ leads to the decrease $\left(Q_{\mathrm{CM}}>0\right)$ or increase $\left(Q_{\mathrm{CM}}<0\right)$ in domain-mean local hydrometeor concentration due to zero hydrometeor convergence as a result of the cyclic horizontal lateral boundaries in the model. The increase in domain-mean surface rain-rate from 4 June to 6 June is largely associated with the increase in domain-mean water vapour convergence $\left(Q_{W V F}>0\right)$, which is consistent with the dominance of large-scale water vapour convergence in the total vapour source from tropical equilibrium cloud-resolving model simulation found by Sui et al. (1994) and in the surface rainfall budget from the cloud-resolving model simulation of a landfall of severe tropical storm Bilis (2006) found by Wang et al. (2009a). The decrease in domain-mean surface rain-rate on 7 June is mainly related to the change to the water vapour divergence $\left(Q_{W V F}<0\right)$ from the water vapour convergence on the previous day (Figure 4). The domain-mean surface rain-rate on 7 June is primarily associated with the domain-mean local atmospheric drying rate $\left(Q_{\mathrm{WvT}}>0\right)$ when the domainmean water vapour divergence occurs.

The daily and model domain-mean heat budgets are also calculated on 4, 6 and 7 June (Figure 5). The heat equation can be found at (A2) in the appendix. Positive values of $S_{\mathrm{RAD}}, S_{\mathrm{HT}}, S_{\mathrm{HF}}, S_{\mathrm{HS}}$ and $S_{\mathrm{LH}}$ denote solar radiative heating, local atmospheric cooling, heat convergence, surface sensible heating and latent heating, respectively. There is an increase in heat divergence from 4 to 6 June 2008 when surface rainfall increases and there is a decrease in heat divergence from 6 to 7 June when surface rainfall decreases (Figure 5). Although the domain-mean water vapour divergence cannot support rainfall on 7 June (Figure 4), the domain-mean heat divergence balances out latent heat. Thus, the domain-mean local atmospheric drying is a result of consumption of water vapour by condensation. Due to low domain-mean radiative cooling rate and a negligibly low domain-mean surface sensible heat rate, the domain-mean heat divergence is largely offset by the domain-mean latent heat. The domainmean heat divergence rates are larger than the domain-mean latent heating rates, which leads to domain-mean local atmospheric cooling $\left(S_{\mathrm{HT}}>0\right)$.

Convective and stratiform rainfall both contribute to model domain-mean surface rainfall. Thus, the surface rainfall budgets are, respectively, calculated over raining stratiform and convective regions using the convective-stratiform rainfall partitioning method developed by Tao et al. (1993) and modified by Sui et al. (1994) (also see appendix). Convective rainfall contributes more to the model domain mean surface rainfall than stratiform rainfall does. The fractional coverage of stratiform and convective rainfall increases from 4 June to 6 June whereas it decreases from 6 June to 7 June (Table II). 


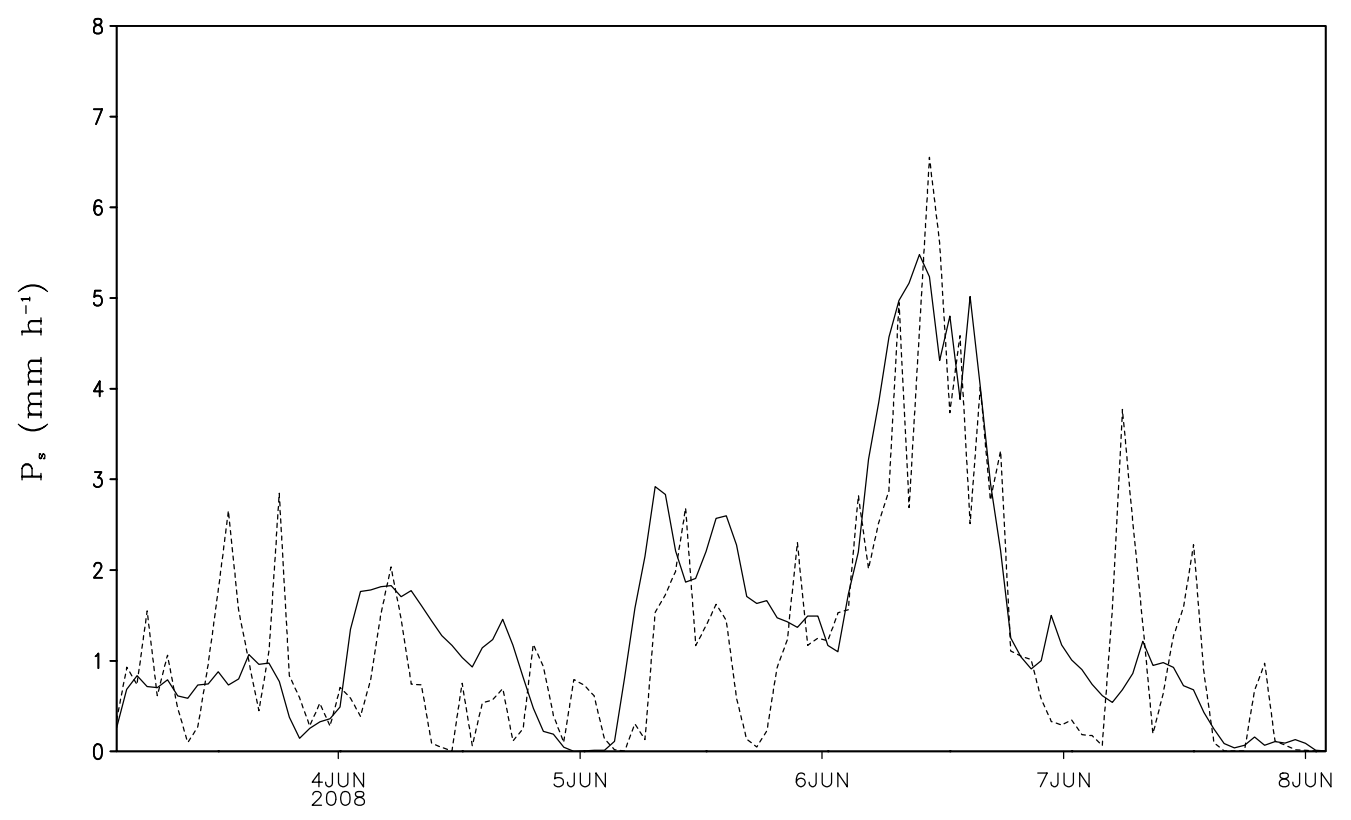

Figure 3. Surface rain-rates $\left(\mathrm{mm} \mathrm{h}^{-1}\right)$ simulated in the control experiment (solid) and from rain-gauge observation (dashed).

On 4 June, the water vapour convergence appears over convective regions whereas the weak water vapour divergence occurs over raining stratiform regions. The convective rainfall is associated with water vapour convergence and local atmospheric drying over convective regions. The negligibly low latent heat rate (not shown) and the large positive value of $Q_{\mathrm{CM}}$ over raining stratiform regions indicate that the stratiform rainfall is mainly supported by the transport of hydrometeor concentration from convective regions to raining stratiform regions.

On 6 June, water vapour convergence is enhanced over both raining stratiform and convective regions. The convective rainfall and the transport of hydrometeor concentration from convective regions to raining stratiform regions cannot be fully supported by the water vapour convergence over convective regions, which leads to local atmospheric drying over convective regions. The water vapour convergence and transport of hydrometeor concentration to raining stratiform regions feed stratiform rainfall.

The domain-mean water vapour divergence occurs one day after the domain-mean surface rainfall reaches its peak, on 7 June (Figure 4). On 7 June, the domainmean water vapour divergence mainly occurs in raining stratiform regions (Figure 6). Over convective regions, the water vapour convergence is not only a source for convective rainfall, it also generates local atmospheric moistening and plays a role in the transport of hydrometeor concentration to raining stratiform regions (Figure 7). Over raining stratiform regions, strong water vapour divergence largely compensates for the strong local atmospheric drying, while the stratiform rainfall is mainly associated with the transport of hydrometeor concentration from convective regions to raining stratiform regions (Figure 6).

To examine the effects of vertical wind shear and cloud radiative processes on rainfall responses to large-scale forcing, the differences in daily-mean surface rainfall and associated budget terms between the sensitivity and control experiments will be calculated and analysed for 4, 6 and 7 June (Figures 4-7).

\subsection{CNVWS vs. C: Effects of vertical wind shear}

The domain-mean surface rainfall budgets (Figure 4) show that the exclusion of vertical wind shear has negligible effects on the water vapour convergence rate and surface rain-rate on 4 and 6 June when the large-scale water vapour convergence corresponds to imposed large-scale upward motions. The $8.7 \%$ increase in domain-mean surface rainrate as a result of the exclusion of vertical wind shear in CNVWS on 7 June is associated with the significant reduction of the water vapour divergence rate and the acceleration of local hydrometeor loss when the water vapour divergence corresponds to the weak imposed largescale upward motions. Rotunno et al. (1988) showed that vertical wind shear allows a spatial separation between the updraught and downdraught, which leads to longer-lived systems and more effective secondary initiation from coldpool outflows. Thus, the exclusion of vertical wind shear may shorten the life span of convective systems, which in turn causes the acceleration of hydrometeor loss. The vertical wind shear has negligible effects on the domain-mean heat budgets during the rainfall (Figure 5).

Secondary circulations are directly responsible for cloud development, and cloud microphysical processes directly produce surface rainfall. The intensity of secondary circulations can be described using perturbation kinetic energy. The linear correlation between model domainmean rain-rate and perturbation kinetic energy is 0.64 , which is statistically significant. The large-scale vertical wind shear is directly responsible for the barotropic conversion between mean domain-mean kinetic energy $(\bar{K})$ and perturbation kinetic energy $\left(K^{\prime}\right)$ in the budget of perturbation kinetic energy through the barotropic conversion between perturbation kinetic energy and domain-mean kinetic energy through the covariance between perturbation zonal wind and vertical velocity under large-scale vertical wind shear $\left(C_{u}\left(\bar{K}, K^{\prime}\right)\right.$; see (A3) in appendix). The budgets of $K^{\prime}$ in $\mathrm{C}$ and CNVWS on 7 June are calculated in Table I and compared to explain the physical mechanism associated with the effects of 

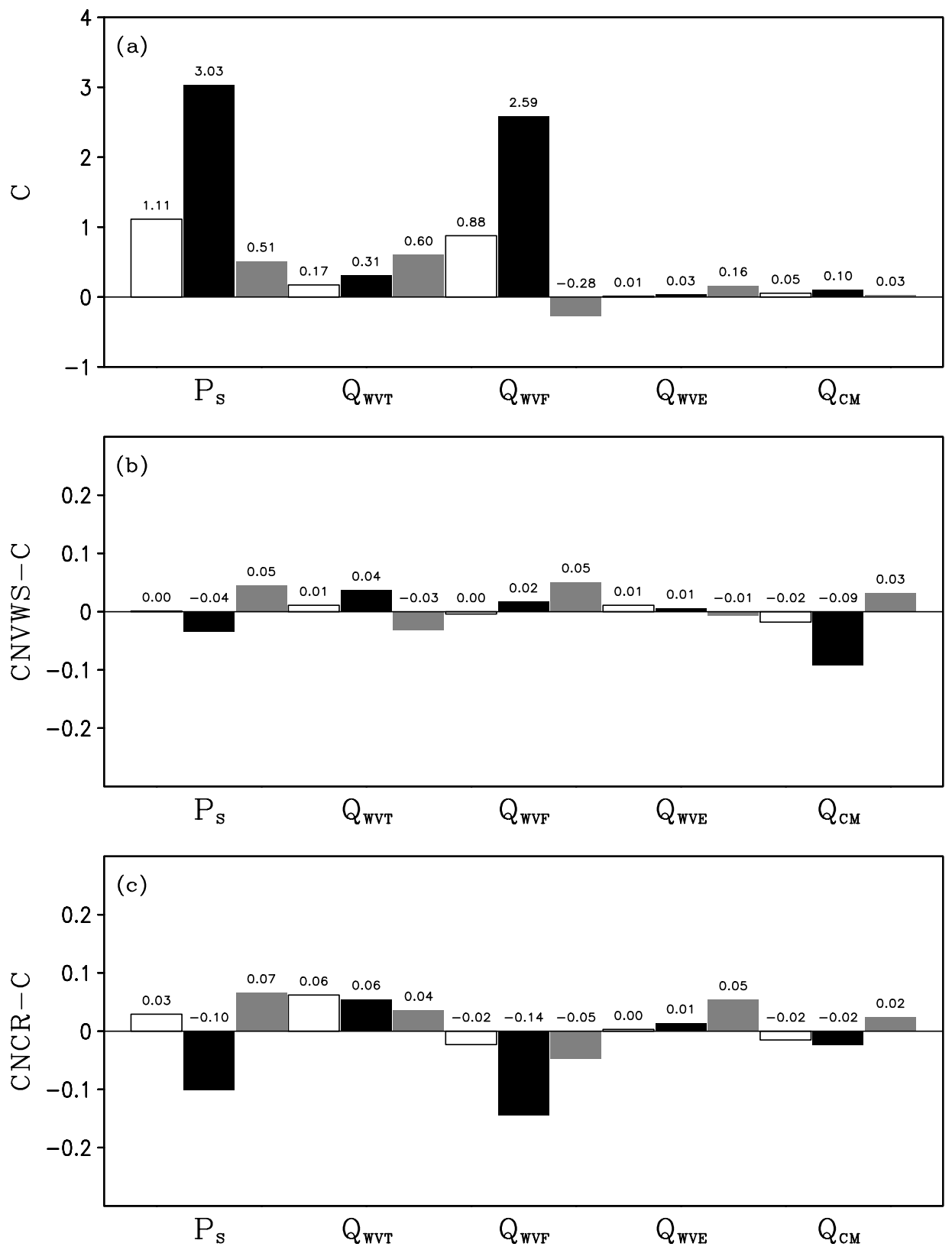

Figure 4. Daily and model domain means of surface rain-rate $\left(P_{\mathrm{S}}\right)$, local water vapour change $\left(Q_{\mathrm{WVT}}\right)$, water vapour convergence $\left(Q_{\mathrm{WVF}}\right)$, surface evaporation $\left(Q_{\mathrm{WVE}}\right)$, local hydrometeor change/hydrometeor convergence $\left(Q_{\mathrm{CM}}\right)$ in the control experiment $(\mathrm{C})$ in $(\mathrm{a})$, and their differences for (b) CNVWS-C and (c) CNCR-C on 4 June (open bar), 6 June (black bar), and 7 June 2008 (grey bar). Unit is $\mathrm{mm} \mathrm{h}^{-1}$.

vertical wind shear on domain-mean surface rain-rate. $C\left(P^{\prime}, K^{\prime}\right)$ and $G_{q \mathrm{v}}\left(K^{\prime}\right)$ are largely balanced by $G_{q 1}\left(K^{\prime}\right)$ in the two experiments (their sums are $-2.9 \times 10^{5} \mathrm{~J} \mathrm{~s}^{-1}$ in $\mathrm{C}$ and $-2.1 \times 10^{5} \mathrm{~J} \mathrm{~s}^{-1}$ in CNVWS). Since these terms are derived from the buoyancy term $g\left(\frac{T}{T_{\mathrm{b}}}+0.61 q_{\mathrm{v}}^{\prime}-q_{\mathrm{l}}^{\prime}\right)$ in the vertical momentum equation, their sum denotes a generalized baroclinic process in the convective system. The difference in the local change rate of perturbation kinetic energy $\left(\frac{\partial K^{\prime}}{\partial t}\right)$ between the two experiments is mainly attributable to the difference in $C_{u}\left(\bar{K}, K^{\prime}\right)$ (a negative value denotes the barotropic conversion from perturbation kinetic energy to domain-mean kinetic energy). The decrease in perturbation kinetic energy in CNVWS is slowed down by the exclusion of barotropic conversion from perturbation kinetic energy to domain-mean kinetic energy as a result of the exclusion of vertical wind shear. Thus, the relative increase of domain-mean surface rain-rates by the exclusion of vertical wind shear in CNVWS is associated with the deceleration of the decrease in perturbation kinetic energy.

On 7 June, $75 \%$ and $25 \%$ of the difference in model domain-mean surface rain-rate for CNVWS-C are, respectively, from the differences in convective and stratiform rain-rate, as both convective and stratiform rainfall cover areas that are about 20\% larger in CNVWS than in C (Table II). Since the water vapour convergence rate over convective regions is lower in CNVWS than in C, the local atmospheric drying over convective regions in CNVWS and the local atmospheric moistening in $\mathrm{C}$ corresponds to higher convective rain-rate in CNVWS than in C (Figure 7).

Although the domain-mean surface rain-rates are similar in the experiments on both 4 and 6 June (Figure 4), the convective and stratiform rain-rates are, respectively, lower and higher in CNVWS than in C (Figures 6 and 7). The fractional coverage of convective and stratiform rainfall 

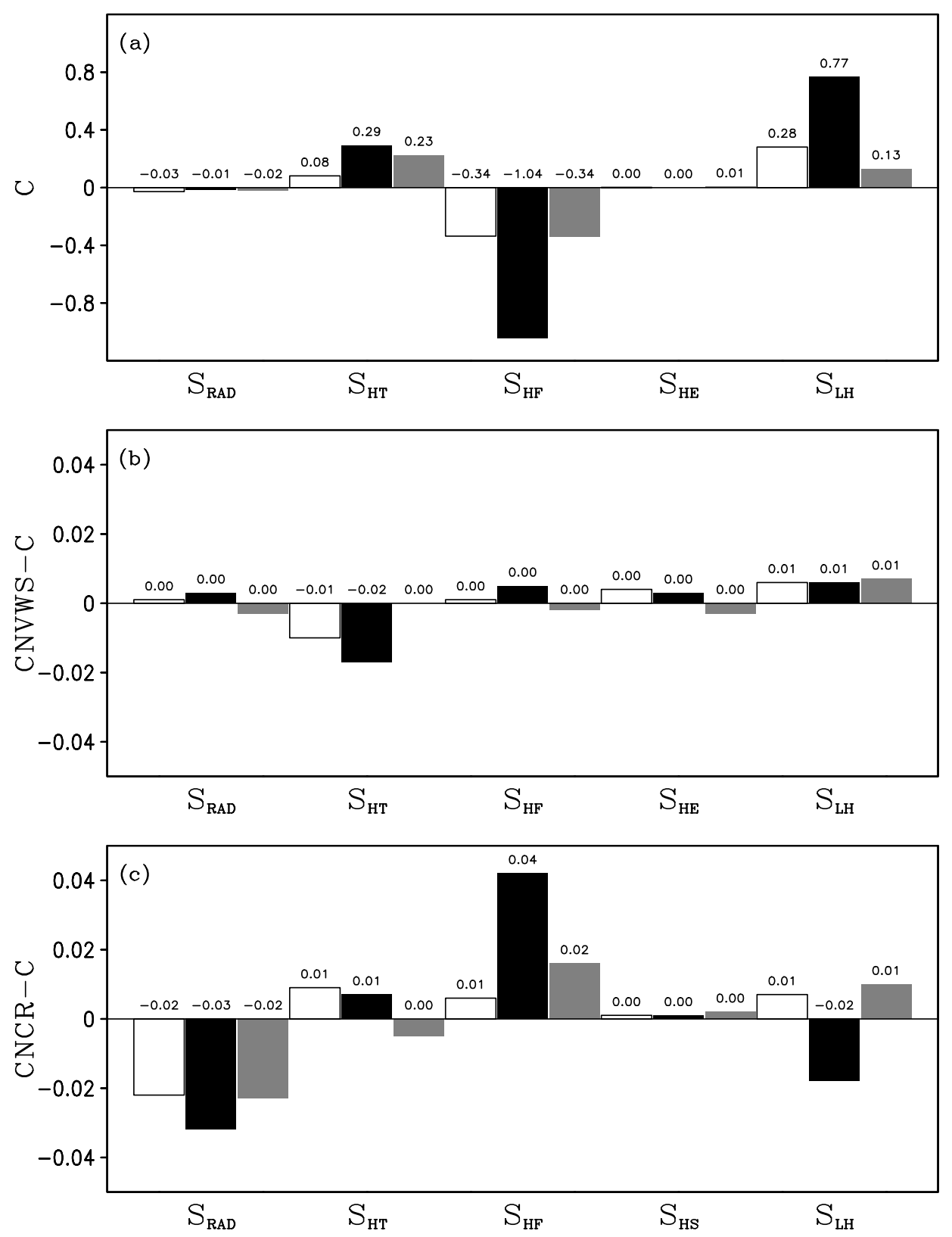

Figure 5. Daily and model domain means of radiative heating $\left(S_{\mathrm{RAD}}\right)$, local heat change $\left(S_{\mathrm{HT}}\right)$, heat convergence $\left(S_{\mathrm{HF}}\right)$, surface sensible flux $\left(S_{\mathrm{HS}}\right)$ and latent heat $\left(S_{\mathrm{LH}}\right)$ in the control experiment $(\mathrm{C})$ in (a), and their differences for (b) CNVWS-C and (c) CNCR-C on 4 June (open bar), 6 June (black bar) and 7 June 2008 (grey bar). Unit is ${ }^{\circ} \mathrm{Ch}^{-1}$.

Table I. Budgets of perturbation kinetic energy $\left(K^{\prime}\right)$ in the control experiment $(C)$ and the experiment with the exclusion of vertical wind shear (CNVWS). $C_{u}\left(\bar{K}, K^{\prime}\right)$ and $C_{w}\left(\bar{K}, K^{\prime}\right)$ are the barotropic conversion between domain-mean kinetic energy $(\bar{K})$ and $K^{\prime}, C\left(P^{\prime}, K^{\prime}\right)$ is the baroclinic conversion between perturbation available potential energy $\left(P^{\prime}\right)$ and $K^{\prime}$, and $G_{q \mathrm{v}}\left(K^{\prime}\right)$ and $G_{q 1}\left(K^{\prime}\right)$ are the generation terms of $K^{\prime}$. Unit is $10^{5} \mathrm{~J} \mathrm{~s}^{-1}$

\begin{tabular}{lllllll}
\hline & $\frac{\partial K^{\prime}}{\partial t}$ & $C_{u}\left(\bar{K}, K^{\prime}\right)$ & $C_{w}\left(\bar{K}, K^{\prime}\right)$ & $C\left(P^{\prime}, K^{\prime}\right)$ & $G_{q \mathrm{v}}\left(K^{\prime}\right)$ & $G_{q \mathrm{l}}\left(K^{\prime}\right)$ \\
\hline $\mathrm{C}$ & -4.9 & -1.9 & 0.0 & 21.5 & 32.3 & -56.7 \\
CNVWS & -2.1 & 0.0 & 0.0 & 13.4 & 31.3 & -46.7 \\
\hline
\end{tabular}

is larger in CNVWS than in C. On 4 and 6 June, the decrease in convective rain-rate by the exclusion of vertical wind shear is mainly associated with the enhanced transport of hydrometeor concentration from convective regions to raining stratiform regions, while the water vapour convergence rates over convective regions are similar in both experiments, and enhanced local atmospheric drying over convective regions is associated with the exclusion of vertical wind shear. The increase in stratiform rain-rate as a result of the exclusion of vertical wind shear is mainly due to enhanced transport of hydrometeor concentration from convective regions to raining stratiform regions on 4 and 6 June, whereas in raining stratiform regions, it is related to the strengthened local atmospheric drying on 

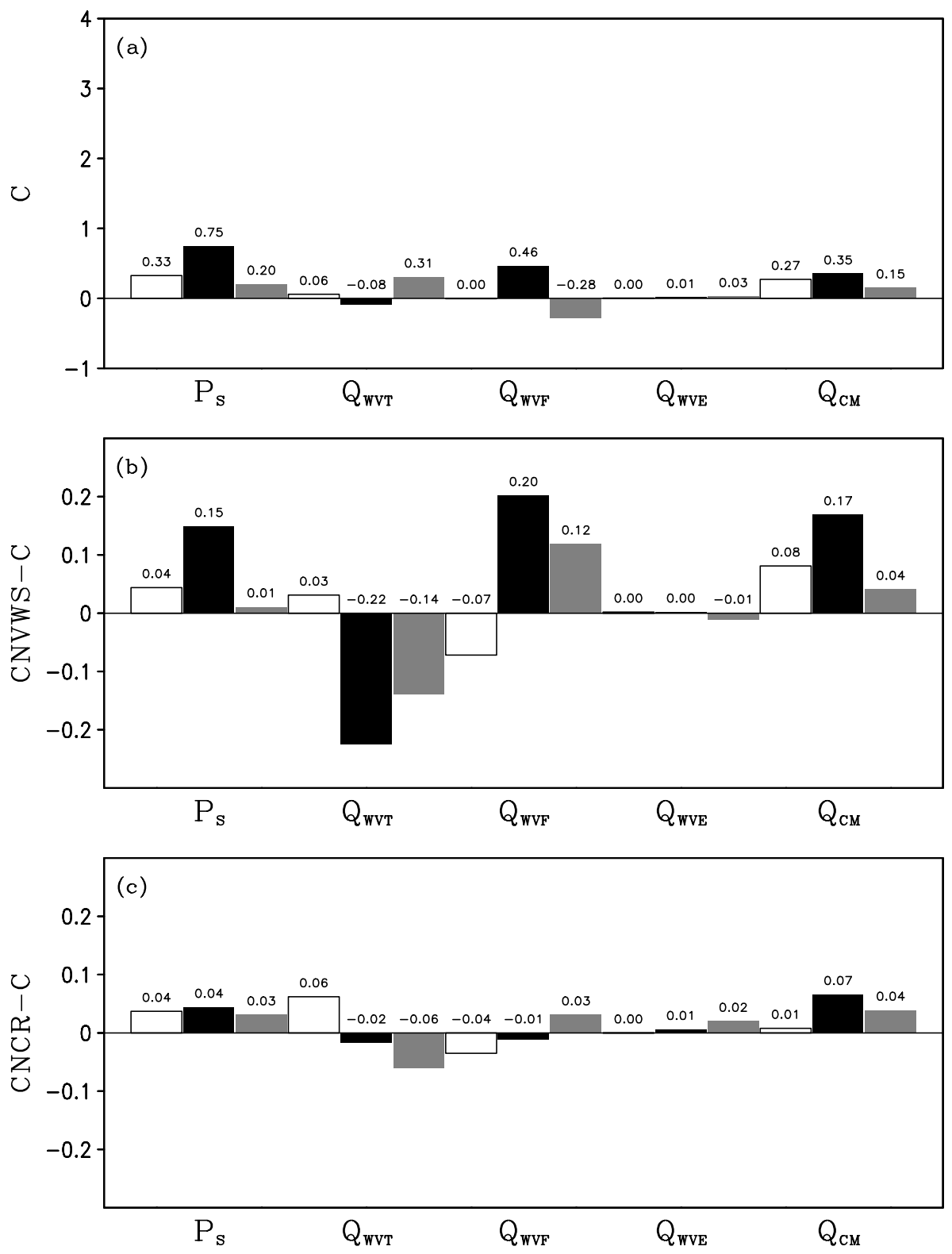

Figure 6. Daily means of surface rain-rate $\left(P_{S}\right)$, local water vapour change $\left(Q_{W V T}\right)$, water vapour convergence $\left(Q_{W V F}\right)$, surface evaporation $\left(Q_{W V E}\right)$, local hydrometeor change/hydrometeor convergence $\left(Q_{C M}\right)$ over raining stratiform regions in the control experiment $(C)$ in (a), and their differences for (b) CNVWS-C and (c) CNCR-C on 4 June (open bar), 6 June (black bar), and 7 June 2008 (grey bar). Unit is $\mathrm{mm} \mathrm{h}^{-1}$.

Table II. Daily means of fractional coverage (\%) of (a) stratiform and (b) convective rainfall in three experiments. The control experiment $(\mathrm{C})$, the experiment with the exclusion of vertical wind shear (CNVWS), the experiment with the exclusion of cloud radiative effects (CNCR), and their differences for CNVWS-C and CNCR-C on 4 June, 6 June and 7 June 2008

\begin{tabular}{llllll}
\hline (a) & C & CNVWS & CNCR & CNVWS-C & CNCR-C \\
\hline 4 June & 20.4 & 20.7 & 21.5 & 0.3 & 1.1 \\
6 June & 33.4 & 38.5 & 37.0 & 5.1 & 3.6 \\
7 June & 11.1 & 13.4 & 12.3 & 2.3 & 1.2 \\
\hline (b) & C & CNVWS & CNCR & CNVWS-C & CNCR-C \\
\hline 4 June & 10.7 & 12.5 & 10.2 & 1.8 & -0.5 \\
6 June & 12.6 & 15.6 & 12.0 & 3.0 & -0.6 \\
7 June & 2.7 & 3.3 & 2.8 & 0.6 & 0.1 \\
\hline
\end{tabular}



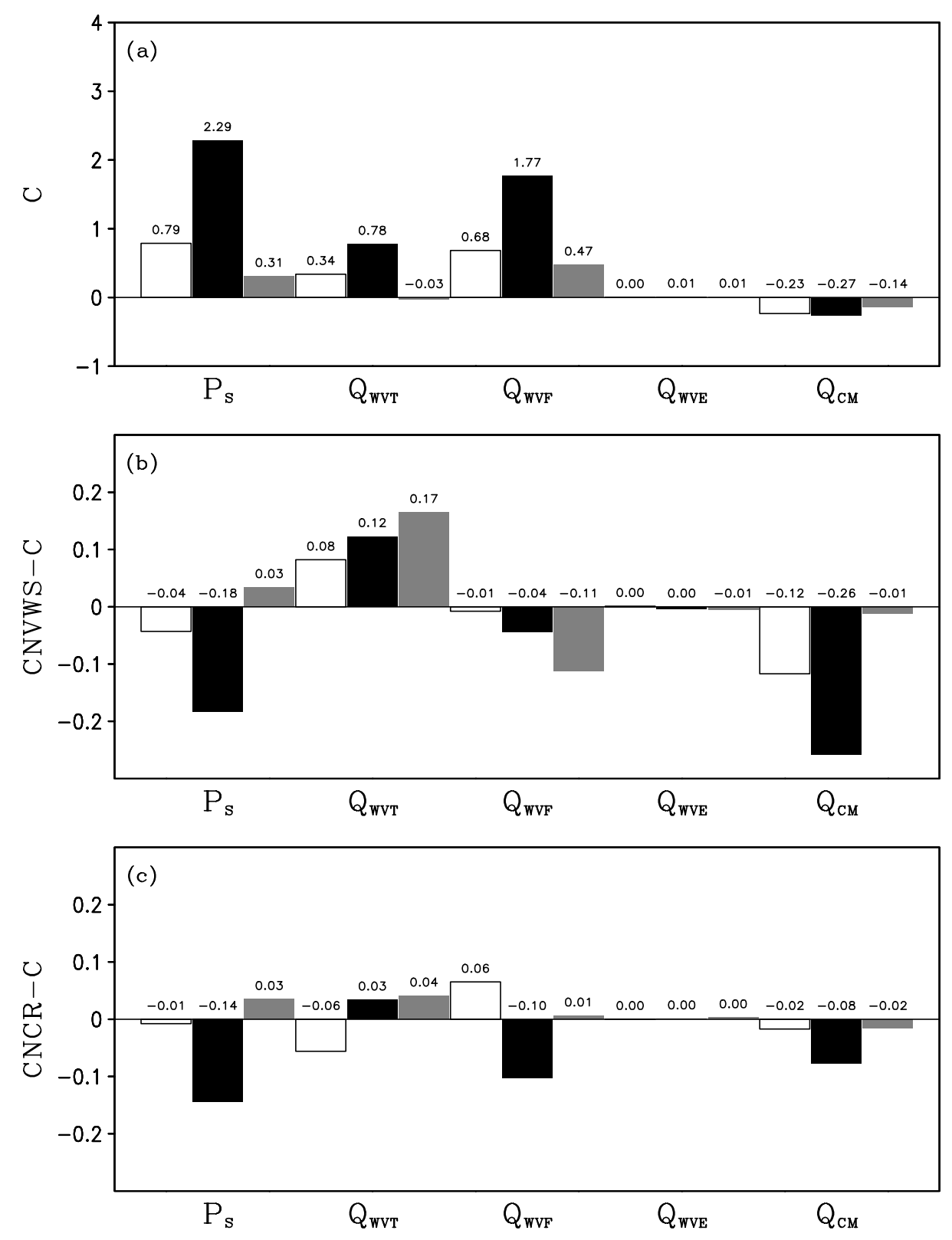

Figure 7. Daily means of surface rain-rate $\left(P_{\mathrm{S}}\right)$, local water vapour change $\left(Q_{\mathrm{WVT}}\right)$, water vapour convergence $\left(Q_{\mathrm{WVF}}\right)$, surface evaporation $\left(Q_{\mathrm{WVE}}\right)$, local hydrometeor change/hydrometeor convergence $\left(Q_{\mathrm{CM}}\right)$ over convective regions in the control experiment $(\mathrm{C})$ in (a), and their differences for (b) CNVWS-C and (c) CNCR-C on 4 June (open bar), 6 June (black bar) and 7 June 2008 (grey bar). Unit is $\mathrm{mm} \mathrm{h}^{-1}$.

4 June and the enhanced water vapour convergence on 6 June.

\subsection{CNCR vs. C: Cloud radiative effects}

On 4 and 6 June, the changes in the domain-mean surface rain-rate by cloud radiative effects are less than $3.3 \%$ (Figure 4 ). The changes in the domain-mean local atmospheric drying rates are largely offset by the change in the domain-mean water vapour convergence rate and the rate of decrease in domain-mean hydrometeor concentration. On 7 June, a $12.8 \%$ increase in domainmean surface rain-rate is generated by the exclusion of cloud radiative effects. The increase in domain-mean surface rain-rate by the exclusion of cloud radiative effects is associated with the increases in surface evaporation and local atmospheric drying and the decrease in domain-mean local hydrometeor concentration.
From observational analysis and numerical modelling, Sui et al. $(1997,1998)$ suggested that the decrease in saturation specific humidity associated with the IR-cooling induced decrease in temperature is a key process in producing a nocturnal rainfall peak. The comparison in domain-mean heat budget between $\mathrm{C}$ and CNCR on 7 June shows that the exclusion of cloud radiative effects in CNCR reduces domain-mean radiative cooling by more than $50 \%$ (Figure 5). Correspondingly, the exclusion of cloud radiative effects increases the domain-mean latent heating rate and decreases the domain-mean heat divergence rate. The increase in domain-mean condensation rate in CNCR is associated with the increase in domain-mean latent heating rate. Thus, in comparison to $\mathrm{C}$, the domain-mean surface rain-rate in CNCR increases.

The differences in domain-mean heat budget between CNCR and C on 4 June are generally similar to those on 7 June. The positive differences in domain-mean 
condensation rate for CNCR-C $\left(P_{\mathrm{S}}-Q_{\mathrm{CM}} \approx 0.42 \mathrm{~mm} \mathrm{~h}^{-1}\right.$ (Figure 4); see cloud budget in Gao and $\mathrm{Li}(2008 \mathrm{~b})$ ) are associated with the positive differences in domainmean latent heating rate $\left(\sim 0.01{ }^{\circ} \mathrm{C} \mathrm{h}^{-1}\right)$ on 4 and 7 June. The difference between 7 and 4 June is that domain-mean hydrometeor concentrations increase $\left(Q_{\mathrm{CM}}=-0.015 \mathrm{~mm} \mathrm{~h}^{-1}\right)$ during the onset phase on 4 June whereas they decrease $\left(Q_{\mathrm{CM}}=0.024 \mathrm{~mm} \mathrm{~h}^{-1}\right)$ during the decay phase on 7 June. Also, the domain-mean surface rain-rate on 7 June is only half of the rain-rate on 4 June. As a result, the increase in domain-mean surface rain-rate from the exclusion of cloud radiative effects on 7 June $(12.8 \%)$ is five times as large as that on 4 June $(2.6 \%)$. The large percentage increase in domain-mean surface rainrate associated with the exclusion of cloud radiative effects during the decay phase is helped by the small domainmean surface rain-rate and acceleration of domain-mean local hydrometeor loss. The large increase in domainmean surface rain-rate in CNCR during the decay phase is consistent with the results found by Gao and $\mathrm{Li}$ (2008a) using an equilibrium cloud-resolving model simulation with zero imposed large-scale vertical velocity.

On 7 June, the convective and stratiform rain-rates are, respectively, $11.3 \%$ and $15.2 \%$ higher in CNCR than in $\mathrm{C}$ (Figures 6 and 7). The stratiform rainfall covers 10.8\% larger areas in CNCR than in $\mathrm{C}$ whereas the convective rainfall occupies similar sizes of areas for both experiments. The enhancement of convective rain-rate by the exclusion of cloud radiative effects is mainly associated with the change of local atmospheric drying in CNCR from local atmospheric moistening in $\mathrm{C}$ over convective regions. The increase in stratiform rain-rate caused by the exclusion of cloud radiative effects is related to the enhanced transport of hydrometeor concentration from convective regions to raining stratiform regions and the weakened water vapour divergence over raining stratiform regions.

The cloud radiative processes generally affect surface rainfall budgets over convective and raining stratiform regions on 4 and 6 June (Figures 6 and 7). The stratiform and convective rainfall cover, respectively, more and less areas in CNCR than in C. On 4 June, the exclusion of cloud radiative effects increases stratiform rain-rate by $11.3 \%$ whereas it has almost no impact on convective rain-rate. On 4 June, the increase in stratiform rain-rate by the exclusion of cloud radiative effects is mainly associated with strengthened local atmospheric drying over raining stratiform regions (Figure 6). The insensitivity of convective rain-rate to cloud radiative effects is from the large cancellation between weakened local atmospheric drying and strengthened water vapour convergence (Figure 7). On 6 June, the exclusion of cloud radiative effects increases stratiform rain-rate by $5.9 \%$ whereas it decreases convective rain-rate by $6.3 \%$. The decrease in convective rain-rate resulting from the exclusion of cloud radiative effects is associated with weakened water vapour convergence over convective regions and strengthened transport of hydrometeor concentration from convective to stratiform regions. The increase in stratiform rain-rate from the exclusion of cloud radiative effects is primarily supported by the strengthened transport of hydrometeor concentration from convective to stratiform regions.

\section{Summary}

The effects of vertical wind shear and cloud radiative effects on responses of 2D idealised cloud-resolving model simulations of pre-summer heavy rainfall over southern China are examined in this study. The control experiment (C) is integrated for 5 days from 0200 LST 3 June to 02008 June 2008 with a model that is forced with zonally-uniform vertical velocity, zonal wind, horizontal temperature and vapour advection from NCEP/GDAS data and is also integrated with the initial vertical profiles spatially uniformly perturbed, respectively, by $\pm 0.2^{\circ} \mathrm{C}$ of temperature and $\pm 1 \%$ of specific humidity in four runs. The five model runs are averaged to form ensemble simulation data. Simulated domain-mean vertical profiles of temperature and specific humidity and surface rain-rate are compared with mean vertical profiles of temperature and specific humidity from NCEP/GDAS data and rain-gauge observations. The two sensitivity experiments are carried out to examine the effects of vertical wind shear and cloud radiative processes on rainfall responses to large-scale forcing. The sensitivity experiments are identical to the control experiment except that the vertically varying large-scale zonal winds are replaced with their mass-weighted means in CNVWS and the hydrometeor mixing ratios are set to zero in the calculations of radiation in CNCR. The analysis is conducted with daily mean budgets calculated from simulation data in three cases: the onset phase on 4 June with the weak model domainmean water vapour convergence and heat divergence, the mature phase on 6 June with strong model domain-mean water vapour convergence and heat divergence, and the decay phase on 7 June with weak model domain-mean water vapour and heat divergence. The major results are:

- The exclusion of vertical wind shear and cloud radiative processes increases the model domain-mean surface rain-rate by $8.7 \%$ and $12.8 \%$, respectively, when the domain-mean water vapour divergence corresponds to the weak imposed large-scale upward motions on 7 June, whereas the exclusion does not impact domain-mean surface rain-rate when the domain-mean water vapour convergence corresponds to the imposed large-scale upward motions on 4 and 6 June.

- On 7 June, the increase in domain-mean surface rain-rate resulting from the exclusion of vertical wind shear is associated with a reduced domain-mean water vapour divergence rate and enhanced domain-mean local hydrometeor loss. The analysis of the budgets of perturbation kinetic energy reveals that the rainrate increase is caused by a slowdown in the decrease of perturbation kinetic energy associated with the exclusion of barotropic conversion from perturbation kinetic energy to domain-mean kinetic energy in CNVWS. The enhancement of domain-mean surface rain-rate by the exclusion of cloud radiative effects in CNCR is associated with an increase in condensation rate and associated latent heating rate due to a decrease in saturation specific humidity caused by an increase in IR cooling rate, and the acceleration of local hydrometeor loss.

- On 7 June, the enhancement of the domain-mean surface rain-rate resulting from the exclusion of vertical wind shear is mainly from convective regions 
where the local water vapour processes are changed from moistening in $\mathrm{C}$ to drying in CNVWS. Both convective and stratiform rain-rates contribute to the increase in domain-mean surface rain-rate from the exclusion of cloud radiative effects. The enhanced convective rain-rate is mainly associated with the change to the local atmospheric drying in CNCR from the local atmospheric moistening in $\mathrm{C}$, whereas the strengthened stratiform rain-rate is associated with the weakened water vapour divergence over raining stratiform regions and the intensified transport of hydrometeor concentration from convective regions to raining stratiform regions.

- Although the domain-mean surface rainfall is much less sensitive to the vertical wind shear and cloud radiative processes on 4 and 6 June than on 7 June, convective and stratiform rainfall processes are affected by these processes. The decrease in convective rain-rate and the increase in stratiform rain-rate from the exclusion of vertical wind shear and cloud radiative processes are mainly associated with the increase of transport rate of hydrometeor concentration from convective regions to raining stratiform regions.

The conclusions above are drawn from idealized 2D cloud-resolving model simulations. Although $2 \mathrm{D}$ and $3 \mathrm{D}$ model simulations show similarities in terms of collective thermodynamic feedback effects, vertical transports of mass, sensible heat and moisture, thermodynamic fields, surface heat fluxes, surface precipitation, precipitation efficiency, and convective and moist vorticity vectors (e.g. Tao and Soong, 1986; Tao et al., 1987; Grabowski et al., 1998; Khairoutdinov and Randall, 2003; Gao et al., 2004, 2005b, 2007; Sui et al., 2005; Zeng et al., 2007), the two types of simulations can also be different. One notable difference is the fact that $2 \mathrm{D}$ model simulations produce stronger convective cold pools than $3 \mathrm{D}$ model simulations do (Tompkins, 2000). Xu et al. (2002) found that differences in $2 \mathrm{D}$ and $3 \mathrm{D}$ model simulations during Atmospheric Radiation Measurement (ARM) are due to the differences between 2D and 3D dynamics. Gao et al. (2005b) and Gao (2007) revealed that convection is highly correlated with the horizontal and vertical components of the dynamic vorticity vector, respectively, in $3 \mathrm{D}$ and $2 \mathrm{D}$ frameworks because dominant items in horizontal components of the $3 \mathrm{D}$ dynamic vorticity vector are excluded from the $2 \mathrm{D}$ framework. Petch (2006) compared 2D and 3D model simulations during the Large-scale Biosphere-Atmosphere (LBA) experiment in Amazonia and showed that the use of the $2 \mathrm{D}$ model has the largest impact on the development of convection, while Stephens et al. (2008) demonstrated the differences in precipitable water and precipitation variability and upper-tropospheric cloud fraction and condensate amount between 2D and 3D model simulations. Therefore, it is necessary to conduct further studies using $3 \mathrm{D}$ cloudresolving model simulations to analyse the effects of largescale vertical wind shear and cloud radiative process on precipitation.

\section{Acknowledgements}

The authors thank W.-K. Tao at NASA/GSFC for his cloud resolving model, N. Sun at I. M. Systems Group, Inc. for technical assistance and three anonymous reviewers for their constructive comments that significantly improved the early version of this manuscript. This study is supported by the National Key Basic Research and Development Project of China under Grant No. 2011CB403405, the National Natural Science Foundation of China under Grant No. 40775033 and 41075039, the Chinese Special Scientific Research Project for Public Interest under Grant No. GYHY200806009, and the Qinglan Project of Jiangsu Province of China under Grant No. 2009.

Appendix. Surface rainfall, heat and kinetic energy budgets, and convective-stratiform rainfall partitioning method

Based on Gao et al. (2005a), Cui and Li (2006), and Gao and $\mathrm{Li}(2008 \mathrm{~b})$, the surface rain-rate $\left(P_{\mathrm{S}}\right)$ can be written as:

$$
P_{\mathrm{S}}=Q_{\mathrm{WVT}}+Q_{\mathrm{WVF}}+Q_{\mathrm{WVE}}+Q_{\mathrm{CM}},
$$

where

$$
\begin{gathered}
Q_{\mathrm{WVT}}=-\frac{\partial\left[q_{\mathrm{v}}\right]}{\partial t}, \\
Q_{\mathrm{WVF}}=-\left[\bar{u}^{o} \frac{\partial \bar{q}_{\mathrm{v}}^{o}}{\partial x}\right]-\left[\bar{w}^{o} \frac{\partial \bar{q}_{\mathrm{v}}}{\partial z}\right] \\
-\left[\bar{w}^{o} \frac{\partial q_{\mathrm{v}}^{\prime}}{\partial z}\right]-\left[w^{\prime} \frac{\partial \bar{q}_{\mathrm{v}}}{\partial z}\right]-\left[\frac{\partial}{\partial x}\left(\bar{u}^{o}+{u^{\prime}}^{\prime} q_{\mathrm{v}}{ }^{\prime}\right],\right. \\
Q_{\mathrm{WVE}}=\left.\bar{\rho}\left(w^{\prime} q_{\mathrm{v}}{ }^{\prime}\right)\right|_{z=z_{\mathrm{b}}}, \\
Q_{\mathrm{CM}}=-\frac{\partial\left[q_{1}\right]}{\partial t}-\left[\frac{\partial}{\partial x}\left(\bar{u}^{o} q_{1}\right)\right]-\left[\frac{\partial}{\partial x}\left(u^{\prime} q_{1}\right)\right] .
\end{gathered}
$$

Here, $Q_{W v T}, Q_{w v F}, Q_{W v e}$ and $Q_{\mathrm{CM}}$ are local water vapour change, water vapour convergence, surface evaporation, and local hydrometeor change/hydrometeor convergence, respectively; $q_{\mathrm{v}}$ is specific humidity; $u$ and $w$ are the zonal and vertical components of wind, respectively; $\bar{\rho}$ is heightdependent mean air density; total hydrometeor mixing ratio $\left(q_{1}\right)$ is the sum of mixing ratios of cloud water $\left(q_{\mathrm{c}}\right)$, raindrops $\left(q_{\mathrm{r}}\right)$, cloud ice $\left(q_{\mathrm{i}}\right)$, snow $\left(q_{\mathrm{s}}\right)$, and graupel $\left(q_{\mathrm{g}}\right)$; overbar denotes a horizontal mean; prime is a perturbation from the horizontal mean; $[()]\left(=\int_{z_{\mathrm{b}}}^{z_{\mathrm{t}}} \bar{\rho}() \mathrm{d} z\right)$ is mass integration, and $z_{\mathrm{t}}$ and $z_{\mathrm{b}}$ are the heights of the top and bottom of the model atmosphere respectively; and superscript ${ }^{\circ}$ is an imposed NCEP/GDAS value.

Following Gao and Li (2008b), the heat budget can be expressed as

$$
S_{\mathrm{HT}}+S_{\mathrm{HF}}+S_{\mathrm{HS}}+S_{\mathrm{LH}}+S_{\mathrm{RAD}}=0
$$

where

$$
\begin{gathered}
S_{\mathrm{HT}}=-\frac{\partial<T>}{\partial t}, \\
S_{\mathrm{HF}}=-<\bar{u}^{o} \frac{\partial \bar{T}^{o}}{\partial x}>-<\pi \bar{w}^{o} \frac{\partial \bar{\theta}}{\partial z}> \\
-<\frac{\partial\left(u^{\prime} T^{\prime}\right)}{\partial x}>-<\bar{u}^{o} \frac{\partial T^{\prime}}{\partial x}> \\
-<\pi \bar{w}^{o} \frac{\partial \theta^{\prime}}{\partial z}>-<\pi w^{\prime} \frac{\partial \bar{\theta}}{\partial z}>,
\end{gathered}
$$




$$
\begin{gathered}
S_{\mathrm{HS}}=H_{\mathrm{s}}, \\
S_{\mathrm{LH}}=\frac{1}{c_{p}}<Q_{\mathrm{cn}}>, \\
S_{\mathrm{RAD}}=\frac{1}{c_{p}}<Q_{\mathrm{R}}>.
\end{gathered}
$$

Here, $S_{\mathrm{HT}}, S_{\mathrm{HF}}, S_{\mathrm{HS}}, S_{\mathrm{LH}}$ and $S_{\mathrm{RAD}}$ are local heat change, heat convergence, surface sensible heat, latent heat, and radiative heating, respectively; $T$ and $\theta$ are air temperature and potential temperature, respectively. $\pi=\left(p / p_{0}\right)^{\kappa}, \kappa=R / c_{p}$, $R$ is the gas constant, $c_{p}$ is the specific heat of dry air at constant pressure $p$, and $p_{0}=1000 \mathrm{hPa}$. $H_{\mathrm{s}}$ is surface sensible heat flux, $Q_{\mathrm{cn}}$ is the condensation heating, $Q_{\mathrm{R}}$ is the net radiative heating due to solar heating and infrared cooling. $<()>\left(=\int_{z_{\mathrm{b}}}^{z_{\mathrm{t}}} \bar{\rho}() \mathrm{d} z / \int_{z_{\mathrm{b}}}^{z_{\mathrm{t}}} \bar{\rho} \mathrm{d} z\right)$ is mass-weighted mean.

Following Li et al. (2002) and Wang et al. (2009b), the equation of perturbation kinetic energy $\left(K^{\prime}\right)$ can be written as

$$
\begin{aligned}
& \frac{\partial K^{\prime}}{\partial t}=C_{u}\left(\bar{K}, K^{\prime}\right)+C_{w}\left(\bar{K}, K^{\prime}\right) \\
& \quad+C\left(P^{\prime}, K^{\prime}\right)+G_{q v}\left(K^{\prime}\right)+G_{q 1}\left(P^{\prime}\right),
\end{aligned}
$$

where

$$
\begin{gathered}
K^{\prime}=\left[\frac{\overline{\left(u^{\prime}\right)^{2}+\left(w^{\prime}\right)^{2}}}{2}\right], \\
C_{u}\left(\bar{K}, K^{\prime}\right)=-\left[\overline{u^{\prime} w^{\prime}} \frac{\partial \bar{u}^{o}}{\partial z}\right], \\
C_{w}\left(\bar{K}, K^{\prime}\right)=-\left[\overline{w^{\prime} w^{\prime}} \frac{\partial \bar{w}^{o}}{\partial z}\right], \\
C\left(P^{\prime}, K^{\prime}\right)=\left[g \frac{\overline{w^{\prime} T^{\prime}}}{T_{\mathrm{b}}}\right], \\
G_{q \mathrm{v}}\left(K^{\prime}\right)=\left[0.61 g \overline{w^{\prime} q_{\mathrm{v}}^{\prime}}\right], \\
G_{q \mathrm{l}}\left(K^{\prime}\right)=-\left[g \overline{w^{\prime} q_{\mathrm{l}}^{\prime}}\right] .
\end{gathered}
$$

Here $g$ is gravitational rate and $T_{\mathrm{b}}$ is initial temperature. $C_{u}\left(\bar{K}, K^{\prime}\right)$ and $C_{w}\left(\bar{K}, K^{\prime}\right)$ are the barotropic conversion between mean domain mean kinetic energy $(\bar{K})$ and $K^{\prime}$, respectively, through covariance between perturbation zonal wind and vertical velocity under vertical shear of imposed horizontal-mean zonal wind, and between perturbation vertical velocities under vertical shear of imposed horizontalmean vertical velocity. $C\left(P^{\prime}, K^{\prime}\right)$ is the baroclinic conversion between perturbation available potential energy $\left(P^{\prime}\right)$ and $K^{\prime}$ through covariance between perturbation vertical velocity and temperature. $G_{q \mathrm{v}}\left(K^{\prime}\right)$ and $G_{q 1}\left(K^{\prime}\right)$ are the generation terms of $K^{\prime}$ through covariance between perturbation vertical velocity and specific humidity, and between perturbation vertical velocity and total hydrometeor mixing ratio, respectively.

The convective-stratiform rainfall partitioning methods have been developed based on the amplitude and spatial variations of radar reflectivity or surface rainfall rate in previous studies (e.g. Churchill and Houze, 1984; Caniaux et al., 1994; Steiner et al., 1995). Additional information like cloud contents, vertical motion, and the fall speed of precipitation particles has been also used in partitioning methods (e.g. Tao and Simpson, 1989; Tao et al., 1993, 2000; Sui et al., 1994; Xu, 1995; Lang et al., 2003). Lang et al. (2003) conducted a comparison study using six different partitioning methods based on surface rain-rate, mass fluxes, apparent heating and moistening, hydrometeor contents, reflectivity and vertical velocity CFAD (Contoured Frequency with Altitude Diagram), microphysics, and latent heat retrieval (Churchill and House, 1984; Tao and Simpson, 1989; Caniaux et al., 1994; Steiner et al., 1995; Xu, 1995; Lang et al., 2003), and showed that the method based on surface rain-rate was consistently the most stratiform whereas the method based on radar information below the melting level and the fall speed of precipitation particles was consistently the most convective.

The convective-stratiform rainfall partitioning method in this study uses rainfall as the main information (Tao et al., 1993) and maximum updraught above $600 \mathrm{hPa}$ and mixing ratio of cloud water as additional information (Sui et al., 1994). When the surface rain-rate at a model grid point is twice as large as the average taken over the surrounding four grid points (two neighbours on each side in the 2D framework), the model grid point and the grid point on either side are considered convective. In addition, any grid point with a rain-rate of $20 \mathrm{~mm} \mathrm{~h}^{-1}$ or more is designated as convective regardless of the above criteria. Additional information on maximum updraught above $600 \mathrm{hPa}$ and cloud water is also used to identify convective rainfall. All non-convective rainfall points are regarded as stratiform. The analysis with this partitioning method shows that the convective rainfall is associated with upward motions throughout the troposphere with a maximum in the lower troposphere, whereas the stratiform rainfall is associated with upward motions in the upper troposphere and downward motions in the lower troposphere (e.g. Gao and Li, 2008b).

\section{References}

Caniaux G, Redelsperger J-L, Lafore J-P. 1994. A numerical study of the stratiform region of a fast-moving squall line. Part I: General description and water and heat budgets. J. Atmos. Sci. 51: 2046-2074. Chou M-D, Suarez MJ. 1994. 'An efficient thermal infrared radiation parameterization for use in general circulation models.' NASA Tech. Memo. 104606, Vol. 3, 85 pp. Available from NASA/Goddard Space Flight Center, Code 913, Greenbelt, MD 20771, USA.

Chou M-D, Kratz DP, Ridgway W. 1991. Infrared radiation parameterizations in numerical climate models. J. Climate 4: 424-437. Chou M-D, Suarez MJ, Ho C-H, Yan MM-H, Lee K-T. 1998. Parameterizations for cloud overlapping and shortwave singlescattering properties for use in general circulation and cloud ensemble models. J. Climate 11: 202-214.

Churchill DD, Houze Jr RA. 1984. Development and structure of winter monsoon cloud clusters on 10 December 1978. J. Atmos. Sci. 41: 933-960. 
Corbosiero KL, Molinari J. 2002. The effects of vertical wind shear on the distribution of convection in tropical cyclones. Mon. Weather Rev. 130: $2110-2123$.

Cui X. 2008. A cloud-resolving modeling study of diurnal variations of tropical convective and stratiform rainfall. J. Geophys. Res. 113: D02113, DOI: 10.1029/2007JD008990.

Cui X, Li X. 2006. Role of surface evaporation in surface rainfall processes. J. Geophys. Res. 111: D17112, DOI: 10.1029/2005JD006876.

Cui X, Li X. 2009. Diurnal responses of tropical convective and stratiform rainfall to diurnally varying sea surface temperature. Meteorol. Atmos. Phys. 104: 53-61.

Ding Y. 1994a. Monsoons over China. Springer.

Ding Y. 1994b. East Asia Monsoon. Meteorological Press: Beijing.

$\mathrm{Fu}$ Q, Krueger SK, Liou KN. 1995. Interactions of radiation and convection in simulated tropical cloud clusters. J. Atmos. Sci. 52: $1310-1328$.

Gao S. 2007. A three-dimensional dynamic vorticity vector associated with tropical oceanic convection. J. Geophys. Res. 112: D18109, DOI: 10.1029/2006JD008247.

Gao S, Li X. 2008a. Cloud-resolving Modeling of Convective Processes. Springer: Dordrecht.

Gao S, Li X. 2008b. Responses of tropical deep convective precipitation systems and their associated convective and stratiform regions to the large-scale forcing. Q. J. R. Meteorol. Soc. 134: 2127-2141.

Gao S, Ping F, Li X, Tao W-K. 2004. A convective vorticity vector associated with tropical convection: A two-dimensional cloudresolving modeling study. J. Geophys. Res. 109: D14106, DOI: 10.1029/2004JD004807.

Gao S, Cui X, Zhou Y, Li X. 2005a. Surface rainfall processes as simulated in a cloud-resolving model. J. Geophys. Res. 110: D10202, DOI: 10.1029/2004JD005467.

Gao S, Cui X, Zhou Y, Li X, Tao W-K. 2005b. A modeling study of moist and dynamic vorticity vectors associated with twodimensional tropical convection. J. Geophys. Res. 110: D17104, DOI: 10.1029/2004JD005675

Gao S, Li X, Tao W-K, Shie C-L, Lang S. 2007. Convective and moist vorticity vectors associated with tropical oceanic convection: A threedimensional cloud-resolving model simulation. J. Geophys. Res. 112: D01105, DOI: 10.1029/2006JD007179.

Grabowski WW, Wu X, Moncrieff MW, Hall WD. 1998. Cloud-resolving modeling of cloud systems during Phase III of GATE. Part II: Effects of resolution and the third spatial dimension. J. Atmos. Sci. 55: 3264-3282.

Khairoutdinov MF, Randall DA. 2003. Cloud resolving modeling of the ARM summer 1997 IOP: Model formulation, results, uncertainties, and sensitivities. J. Atmos. Sci. 60: 607-625.

Krishnamurti TN, Molinari J, Pan HL. 1976. Numerical simulation of the Somali Jet. J. Atmos. Sci. 33: 2350-2362.

Krueger SK, Fu Q, Liou KN, Chin H-NS. 1995. Improvement of an icephase microphysics parameterization for use in numerical simulations of tropical convection. J. Appl. Meteorol. 34: 281-287.

Lang S, Tao W-K, Simpson J, Ferrier B. 2003. Modeling of convective-stratiform precipitation processes: Sensitivity to partitioning methods. J. Appl. Meteorol. 42: 505-527.

Lang S, Tao W-K, Cifelli R, Olson W, Halverson J, Rutledge S, Simpson J. 2007. Improving simulations of convective systems from TRMM LBA: Easterly and westerly regimes. J. Atmos. Sci. 64: 1141-1164.

Li X, Sui C-H, Lau K-M, Chou M-D. 1999. Large-scale forcing and cloud-radiation interaction in the tropical deep convective regime. J. Atmos. Sci. 56: 3028-3042.

Li X, Sui C-H, Lau K-M. 2002. Interactions between tropical convection and its environment: An energetics analysis of a $2 \mathrm{D}$ cloud resolving simulation. J. Atmos. Sci. 59: 1712-1722.

Lin Y-L, Farley RD, Orville HD. 1983. Bulk parameterization of the snow field in a cloud model. J. Clim. Appl. Meteorol. 22: 1065-1092.

Pastushkov RS. 1975. The effects of vertical wind shear on the evolution of convective clouds. Q. J. R. Meteorol. Soc. 101: 281-291.

Petch JC. 2006. Sensitivity studies of developing convection in a cloudresolving model. Q. J. R. Meteorol. Soc. 132: 345-358.

Ping F, Luo Z. 2009. Microphysical and radiative effects of ice clouds on diurnal variations of tropical convective and stratiform rainfall. Atmos. Res. 93: 862-873.

Randall DA, Xu K-M, Somerville RJC, Iacobellis S. 1996. Single-column models and cloud ensemble models as links between observations and climate models. J. Climate 9: 1683-1697.

Robe FR, Emanuel KA. 2001. The effect of vertical wind shear on radiative-convective equilibrium states. J. Atmos. Sci. 58: 1427-1445.

Rotunno R, Klemp JB, Weisman ML. 1988. A theory for strong, long-lived squall lines. J. Atmos. Sci. 45: 463-485.

Rutledge SA, Hobbs PV. 1983. The mesoscale and microscale structure and organization of clouds and precipitation in midlatitude cyclones.
VIII: A model for the 'seeder-feeder' process in warm-frontal rainbands. J. Atmos. Sci. 40: 1185-1206.

Rutledge SA, Hobbs PV. 1984. The mesoscale and microscale structure and organization of clouds and precipitation in midlatitude cyclones. XII: A diagnostic modeling study of precipitation development in narrow cold-frontal rainbands. J. Atmos. Sci. 41: 2949-2972.

Simmonds I, Bi D, Hope P. 1999. Atmospheric water vapor flux and its association with rainfall over China in summer. J. Climate 12 $1353-1367$.

Soong S-T, Ogura Y. 1980. Response of tradewind cumuli to large-scale processes. J. Atmos. Sci. 37: 2035-2050.

Soong ST, Tao W-K. 1980. Response of deep tropical cumulus clouds to mesoscale processes. J. Atmos. Sci. 37: 2016-2034.

Steiner M, Houze Jr RA, Yuter SE. 1995. Climatological characterization of three-dimensional storm structure from operational radar and rain gauge data. J. Appl. Meteorol. 34: 1978-2007.

Stephens GL, van den Heever S, Pakula L. 2008. Radiative-convective feedbacks in idealized states of radiative-convective equilibrium. $J$ Atmos. Sci. 65: 3899-3916.

Sui C-H, Lau K-M, Tao W-K, Simpson J. 1994. The tropical water and energy cycles in a cumulus ensemble model. Part I: Equilibrium climate. J. Atmos. Sci. 51: 711-728.

Sui C-H, Lau K-M, Takayabu YN, Short DA. 1997. Diurnal variations in tropical oceanic cumulus convection during TOGA COARE. J. Atmos. Sci. 54: 639-655.

Sui C-H, Li X, Lau K-M. 1998. Radiative-convective processes in simulated diurnal variations of tropical oceanic convection. J. Atmos. Sci. 55: 2345-2357.

Sui C-H, Li X, Yang M-J, Huang H-L. 2005. Estimation of oceanic precipitation efficiency in cloud models. J. Atmos. Sci. 62: 4358-4370. Sui C-H, Li X, Yang M-J. 2007. On the definition of precipitation efficiency. J. Atmos. Sci. 64: 4506-4513.

Tao S-Y, Ding Y-H. 1981. Observational evidence of the influence of the Qinghai-Xizang (Tibet) plateau on the occurrence of heavy rain and severe convective storms in China. Bull. Am. Meteorol. Soc. 62: 23-30.

Tao W-K, Simpson J. 1989. Modeling study of a tropical squall-type convective line. J. Atmos. Sci. 46: 177-202.

Tao W-K, Simpson J. 1993. The Goddard Cumulus Ensemble model. Part I: Model description, Terr. Atmos. Oceanic Sci. 4: 35-72.

Tao W-K, Soong S-T. 1986. A study of the response of deep tropical clouds to mesoscale processes: Three-dimensional numerical experiments. J. Atmos. Sci. 43: 2653-2676.

Tao W-K, Simpson J, Soong S-T. 1987. Statistical properties of a cloud ensemble: A numerical study. J. Atmos. Sci. 44: 3175-3187.

Tao W-K, Simpson J, McCumber M. 1989. An ice-water saturation adjustment. Mon. Weather Rev. 117: 231-235.

Tao W-K, Simpson J, Sui C-H, Ferrier B, Lang S, Scala J, Chou M-D, Pickering K. 1993. Heating, moisture, and water budgets of tropical and midlatitude squall lines: Comparisons and sensitivity to longwave radiation. J. Atmos. Sci. 50: 673-690.

Tao W-K, Lang S, Simpson J, Olson WS, Johnson D, Ferrier B, Kummerow C, Adler R. 2000. Vertical profiles of latent heat release and their retrieval for TOGA COARE convective systems using a cloud resolving model, SSM/I, and ship-borne radar data. J. Meteorol. Soc. Jpn 78: 333-355.

Tompkins AM. 2000. The impact of dimensionality on long-term cloudresolving model simulations. Mon. Weather Rev. 128: 1521-1535.

Ueno M. 2007. Observational analysis and numerical evaluation of the effects of vertical wind shear on the rainfall asymmetry in the typhoon inner-core region. J. Meteorol. Soc. Jpn 85: 115-136.

Wang D, Li X, Tao W=K, Liu Y, Zhou H. 2009a. Torrential rainfall processes associated with a landfall of severe tropical storm Bilis (2006): A two-dimensional cloud-resolving modeling study. Atmos. Res. 91: 94-104.

Wang D, Li X, Tao W-K, Wang Y. 2009b. Effects of vertical wind shear on convective development during a landfall of severe tropical storm Bilis (2006). Atmos. Res. 94: 270-275.

Wang J-Z, Li M-C. 1982. Cross-equator flow from Australia and summer monsoon circulations and precipitation over China. Sci. Atmos. Sin. 6: $1-10$.

Wu X, Yanai M. 1994. Effects of vertical wind shear on the cumulus transport of momentum: Observations and parameterization. J. Atmos. Sci. 51: 1640-1660.

Xu K-M. 1995. Partitioning mass, heat, and moisture budgets of explicitly simulated cumulus ensembles into convective and stratiform components. J. Atmos. Sci. 52: 551-573.

$\mathrm{Xu}$ K-M, Randall DA. 1995. Impact of interactive radiative transfer on the macroscopic behavior of cumulus ensembles. Part II: Mechanisms for cloud-radiation interactions. J. Atmos. Sci. 52: 800-817. 
Xu K-M, Arakawa A, Krueger SK. 1992. The macroscopic behavior of cumulus ensembles simulated by a cumulus ensemble model. J. Atmos. Sci. 49: 2402-2420.

Xu K-M, Cederwall RT, Donner LJ, Grabowski WW, Guichard F, Johnson DE, Khairoutdinov M, Krueger SK, Petch JC, Randall DA Seman CJ, Tao W-K, Wang D, Xie SC, Yio JJ, Zhang M-H. 2002. An intercomparison of cloud-resolving models with the Atmospheri Radiation Measurement summer 1997 Intensive Observation Period data. Q. J. R. Meteorol. Soc. 128: 593-624.
$\mathrm{Xu} \mathrm{X}, \mathrm{Xu} \mathrm{F}, \mathrm{Li}$ B. 2007. A cloud-resolving modeling study of a torrential rainfall event over China. J. Geophys. Res. 112: D17204, DOI: 10.1029/2006JD008275.

Zeng X, Tao W-K, Zhang M, Peters-Lidard C, Lang S, Simpson J, Kumar S, Xie S, Eastman JL, Shie C-L, Geiger JV. 2007. Evaluating clouds in long-term cloud-resolving model simulations with observational data. J. Atmos. Sci. 64: 4153-4177.

Zhou Y, Li X. 2009. Sensitivity of convective and stratiform rainfall to sea surface temperature. Atmos. Res. 92: 212-219. 